From the Agency for Healthcare Research and Quality

Ann Fam Med 2014;284. doi: 10.1370/afm.1650.

\section{AHRQ UPDATES ON PRIMARY CARE RESEARCH: MCC RESEARCH NETWORK DATA ARCHIVE}

Scientists studying people with multiple chronic conditions (MCC) need new datasets and research methods to help them examine this growing population. The MCC Research Network data archive (http://www.icpsr.umich.edu/AHRQMCC/) from the Agency for Healthcare Research and Quality (AHRQ) seeks to fill this gap. Using datasets freely available in the data archive, researchers can investigate the interactions of chronic conditions, compare outcomes from different treatments, and discover the most efficient and effective methods of treating patients with MCC.

\section{Find Data}

AHRQ's MCC Research Network data archive provides freely available datasets and documentation as well as additional MCC-related data. Data come from a rich range of sources, including: electronic medical record clinical data, multi-payer claims data, chronic disease registries, Medicaid claims, state psychiatric hospital inpatient data and outpatient mental health services, self-reported home blood sugar and blood pressure data, state cancer registry data, and qualityof-life and physical assessment data obtained from computer-assisted interviews. For many datasets in the archive, researchers can search for variables, studies, and bibliographies, as well as download data in SPSS SAS, Stata, and ASCII formats.

\section{Share Data}

In addition, investigators with MCC-related data are invited to share their data through the AHRQ MCC Research Network data archive. Data deposited in the archive will be freely available for download from the website until at least December 2015. After that time, the datasets will be accessible to Inter-university Consortium for Political and Social Science Research (ICPSR) members (which includes most institutions) and available for a cost to non-members. Shared data may include complete data sets, partial data, data documentation, and/or syntax files used to replicate findings. Data released for public dissemination can include: SAS, SPSS, and Stata data files, searchable PDF codebooks, and summary metadata records.
The website also includes a page for investigators to share code, syntax, software, methods, and other tools that they have used in their MCC research to help other investigators working on MCC research.

For more information on the AHRQ MCC Research Network and the data archive, please visit the AHRQ MCC website: http://www.ahrq.gov/research/ mccrn.htm.

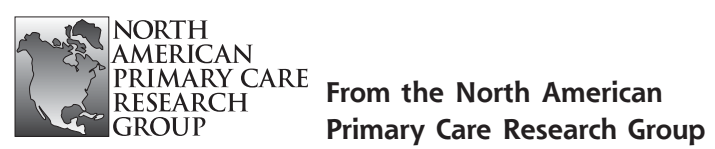

Ann Fam Med 2014;284-285. doi: 10.1370/afm.1656.

\section{TELL US A STORY ABOUT WHEN PRIMARY CARE WORKED FOR YOU}

The title above appropriately reflects the theme of the first Patient-Centered Primary Care Policy and Advocacy Preconference, held in conjunction with the 2013 NAPCRG Annual Meeting in Ottawa, Ontario, Canada, November 2013. This conference brought together 10 dyads, shown in Table 1, of patients and their primary care providers to learn about primary care, primary care research, and patient-centered outcomes research. The interactive conference included a full-day preconference, attendance at NAPCRG research presentations, and a second half-day debrief and learning group held towards the end of the NAPCRG meeting. The preconference featured several lectures from Perry Dickinson and Valerie Gilchrist, plenty of small group discussion and storytelling, and a lunch conversation with Joseph Selby, Director of the Patient-Centered Outcomes Research Institute (PCORI); David Meyers, Agency for Healthcare Research and Quality (AHRQ); and Nancy Mason MacLellan, Deputy Director, Program Delivery Research Capacity Development, Canadian Institutes of Health Research.

\section{Table 1. Patient and Provider Participants}

Ed Bujold, MD, and Ray Haeme

Kristen Dillon, MD, and Susan Lowe

Cynthia Krueger Wolff, MD, and Bethene Kay Ross

Tony Gerk, MD, and Christin Sutter, Ned Norman, and Maret Felzien, MA

Joesph Lemaster, MD, MPH, and Mang Sonna

Marilyn Fraser, MD, and Ruthann Taylor

Cleo Mavriplis, MD, and Madeleine L Champagne

Ann Macauley, MD, and Jean Légaré

Antoine Boivin, MD, and Jean Vocino 